Revista Eletrônica em Gestão, Educação e Tecnologia Ambiental

REGET/UFSM (e-ISSN: 2236-1170).

\title{
GESTÃO DE RESÍDUOS SÓLIDOS NA INDÚSTRIA DE BENEFICIAMENTO DE ARROZ
}

\author{
Ana Paula Fleig Saidelles, Ana Júlia Teixeira Senna, Rosane Kirchner, Gabriele Bitencourt
}

\begin{abstract}
Resumo: Atualmente, a dimensão ambiental está adquirindo, cada vez mais, importância nas ações das organizações e da sociedade. Hoje, os produtos são freqüentemente idealizados, produzidos, comercializados e consumidos levando em conta os impactos gerados em cada processo da cadeia produtiva orizícola. Uma grande preocupação deste setor é com os resíduos sólidos gerados na indústria de beneficiamento do arroz. Por isso, este trabalho tem como objetivo identificar os resíduos sólidos oriundos de uma agroindústria beneficiadora de arroz e propor melhorias para a sua destinação. Essa pesquisa foi realizada em uma agroindústria beneficiadora de arroz, localizada no município de São Sepé/RS, no período entre os meses de abril a junho de 2010. O mapeamento adotado segue uma observação estruturada. Foram identificados no mapeamento vinte e um tipos de resíduos resultantes do processo, sendo os que foram observados em maior quantidade a cinza e a casca de arroz. O diagnóstico realizado permite a empresa conhecer melhor o seu funcionamento, propor melhorias e fazer uma revisão periódica dos resíduos sólidos gerados no processo produtivo. Por fim, se propôs estratégias para o redirecionamento dos resíduos minimizando problemas ambientais.
\end{abstract}

Palavras-chave: agroindústria, gestão ambiental, sustentabilidade

\section{Solid waste management in rice processing industries}

Abstract: Nowadays, the environmental dimension is increasingly receiving more and more importance in organizations and society actions. Today, products are frequently designed, produced, marketed and consumed, taking into account the impact produced by each process in the rice crop production chain. A major concern in this sector is with the solid waste produced by the rice processing industry. Thus, this work aims at identifying the solid waste produced at rice processing agroindustry and, to come up with improvement possibilities for the destination of this solid waste. This research was carried out at a rice processing agroindustry located at the city of São Sepé/RS from April to June 2010. The mapping process adopted follows a structured observation. Through this mapping it was possible to identify twenty and one different types of wastes resulting from the rice processing, with ash and rice husk being the ones observed in greater quantity. The diagnose we performed allows the industry to better know its own operation and then, propose improvements and, to perform a periodic review of the solid wastes produced during the production process. Finally, we suggested some strategies for the waste for redirecting the waste minimizing the environmental problems.

Key words: agroindustry, environmental management, sustainability

\section{INTRODUÇÃO}

Nas últimas décadas, as organizações estão buscando minimizar os impactos ambientais causados pelo homem utilizando estratégias ambientais sustentáveis como forma de diferenciação e agregação de valor (Dias, 2009; Senna \& Lhamby, 2010). Com a escassez das 


\section{Revista Eletrônica em Gestão, Educação e Tecnologia Ambiental REGET/UFSM (e-ISSN: 2236-1170).}

matérias primas não renováveis e o volume de resíduos sólidos gerados nos processos produtivos, a alternativa mais adequada é o aproveitamento dos rejeitos industriais (Menezes et al., 2002).

Os resíduos são produzidos e, quando não são bem destinados, podem levar a destruição de paisagem, fauna e flora. Uma das formas de minimizar os impactos é a preservação dos recursos naturais ou a reutilização de resíduos.

$\mathrm{Na}$ indústria, a quantidade de resíduos gerados é considerada elevada. As atividades industriais são responsabilizadas, muitas vezes, por contaminações e acidentes ambientais, principalmente, pelo acúmulo de matérias primas, insumos, transporte, disposição inadequada e ineficiência da geração de resíduos (Freire et al., 2000).

O resíduo industrial, depois de gerado, necessita de destino adequado, pois, além de criar potenciais problemas ambientais, os resíduos representam perdas de matérias primas e energia, exigindo investimentos significativos em tratamentos para controlar a poluição. A indústria de alimentos produz vários resíduos de alto valor de (re)utilização (Pelizer et al., 2007).

No processo produtivo das indústrias existe uma grande diversidade de resíduos formados que podem poluir o solo, a água e o ar. Sendo assim, é importante observar o tipo de resíduo gerado pela indústria e qual seu poder impactante ao meio ambiente (Ferreira, 2010).

Muitas indústrias associaram as questões ambientais aos seus processos produtivos, através dos denominados Sistemas de Gestão Ambiental (SGA) (Silva \& Amaral, 2004). O sucesso do SGA de uma indústria depende da relação entre os aspectos ambientais ligados aos processos de produção, aos produtos e aos serviços (Nicolella et al., 2004).

O SGA deve ser implantado de forma integrada ao gerenciamento global de uma organização pública ou privada. A ação do SGA não deve ocorrer de forma isolada do gerenciamento da empresa. O meio ambiente não deve ficar restrito a uma sala, departamento ou conjunto de pessoas que atuam de forma isolada na empresa, mas permear toda a organização. Isto evidencia a importância estratégica que a dimensão ambiental está assumindo nas organizações (Albuquerque, 2010).

Nas empresas, a gestão dos resíduos, é considerada uma atividade complexa que contempla desde o mapeamento dos resíduos gerados até a verificação da viabilidade técnica e econômica de prevenir e minimizar a geração de cada resíduo, segregá-lo, classificá-lo, identificá-lo e armazená-lo de forma adequada até o transporte e a destinação final (Andrade \& Chiuvite, 2004).

Uma das primeiras etapas é o mapeamento da geração de resíduos, que deve ser realizado no formato de tabelas, identificando e caracterizando os resíduos gerados em cada setor e sua destinação de forma generalizada (Andrade \& Chiuvite, 2004).

Em particular, a indústria de alimentos produz uma série de resíduos com potencial valor de reutilização. O setor orizícola destaca-se entre os setores que tem demonstrado preocupação com o meio ambiente e têm adotado medidas visando a redução dos impactos ambientais decorrentes das externalidades do sistema produtivo. 


\section{Revista Eletrônica em Gestão, Educação e Tecnologia Ambiental REGET/UFSM (e-ISSN: 2236-1170).}

O arroz é um dos cereais mais cultivados no mundo e é responsável pela base alimentar de grandes contingentes humanos. Segundo Silva et al. (2003), inúmeros esforços são realizados visando à manutenção da qualidade dos grãos desta cultura nas diversas operações de póscolheita.

No Brasil, segundo Vieira \& Carvalho (1999), o arroz é consumido, principalmente, na forma de grãos inteiros, como produto de mesa, sendo mais conhecidos três tipos de produtos: o arroz integral (descascado), o arroz branco (polido) e o arroz parboilizado, os quais são oriundos do arroz em casca e obtidos por diferentes processos de pós-colheita que geram mudanças físicas, químicas e estruturais nos grãos.

O objetivo deste trabalho é identificar os resíduos sólidos oriundos de uma agroindústria beneficiadora de arroz e propor melhorias para a redução desses resíduos contaminantes no meio ambiente. $O$ instrumental descritivo do beneficiamento agroindustrial do arroz e a abordagem de gestão de resíduos sólidos permitem identificar com mais clareza as principais etapas do processo agroindustrial e os resíduos eliminados em cada etapa que deverão ser minimizados. Ademais, poucos trabalhos têm sido publicados, no meio acadêmico, analisando a gestão de resíduos na cadeia agroindustrial do arroz.

\section{MATERIAL E MÉTODOS}

A pesquisa foi realizada em uma agroindústria beneficiadora de arroz, localizada no município de São Sepé, no estado do Rio Grande do Sul. A cidade de São Sepé possui uma área territorial de $2.200,702 \mathrm{Km}^{2}$ ocupados por uma população de 23.798 habitantes (IBGE, 2010). Segundo dados do IBGE de 2009 são cultivados cerca de 20.000 ha de arroz em São Sepé, sendo esta uma das principais culturas do município.

Os procedimentos utilizados para a realização da coleta de dados primários foram a observação e a entrevista em profundidade.

A observação consiste em um registro, de forma sistemática, dos padrões de comportamento das pessoas, objetos e eventos, para obter informações sobre o fenômeno de interesse. 0 observador não interroga as pessoas que estão sendo observadas, nem se comunica com elas (Malhotra, 2001).

Neste trabalho adotou-se a observação estruturada que, segundo Malhotra (2001), é uma técnica de observação em que o pesquisador define claramente os comportamentos a serem observados e os métodos pelos quais serão avaliados. No caso desta pesquisa, realizaram-se as observações no período compreendido entre os meses de abril a junho de 2010. Neste período, procedeu-se a identificação dos resíduos gerados na indústria de processamento de arroz.

Foi realizada uma entrevista em profundidade com a gerente de produção da agroindústria beneficiadora de arroz, que seguiu um protocolo de entrevistas semi-estruturado, diretamente relacionado com o referencial teórico sobre gestão ambiental e gestão de resíduos sólidos. 


\section{Revista Eletrônica em Gestão, Educação e Tecnologia Ambiental REGET/UFSM (e-ISSN: 2236-1170).}

Nas questões abertas foi realizada a análise descritiva dos dados coletados. O processo iniciouse com a identificação das respostas que se igualassem ou se assemelhassem. Posteriormente, as informações coletadas foram agrupadas em tabelas.

Para elaboração deste trabalho foi realizado o mapeamento e a identificação da geração de resíduos, conforme Andrade \& Chiuvite (2004), na indústria de processamento de arroz. Posteriormente, foi realizada a classificação de resíduos de acordo com a NBR 10.004/2004, a descrição do sistema de produção do beneficiamento do arroz, a estimativa da quantidade gerada, tipo/formas de armazenamento e o destino final mais adequado para cada resíduo da empresa em questão.

\section{RESULTADOS E DISCUSSÕES}

Primeiramente, foi realizado o mapeamento do processo de beneficiamento de arroz, conforme a metodologia proposta por Andrade \& Chiuvite (2004), fazendo-se o levantamento dos resíduos gerados em toda a indústria. Realizou-se a identificação dos pontos de geração de resíduos e a observação das características de cada material residual (ver Tabela 1).

Tabela 1. Mapeamento de Resíduos de uma Indústria de Beneficiamento de Arroz

\begin{tabular}{|c|c|c|c|c|c|}
\hline Resíduo & Fonte geradora & $\begin{array}{l}\text { Quantidade } \\
\text { gerada } \\
\text { (estimativa } \\
\text { aprox.) }\end{array}$ & $\begin{array}{l}\text { Freqüência de } \\
\text { geração }\end{array}$ & $\begin{array}{l}\text { Estado } \\
\text { físico }\end{array}$ & Composição Aprox. \\
\hline Casca de arroz & $\begin{array}{c}\text { Setor de } \\
\text { beneficiamento }\end{array}$ & 800 toneladas & Diário & Sólido & $\begin{array}{l}\text { Proteína, gordura, lignina; } \\
\text { fibras, composto de nitrogênio; } \\
\text { lipídeo; carboidratos, sílica }\end{array}$ \\
\hline Cinza & $\begin{array}{l}\text { Secador e } \\
\text { fornalha }\end{array}$ & $54 \mathrm{~m}^{3}$ & Diário & Sólido & $\begin{array}{c}\text { Sílica; } \mathrm{SiO}_{2} . \mathrm{Al}_{2} \mathrm{O}_{3} ; \mathrm{Fe}_{2} \mathrm{O}_{3} ; \mathrm{CaO} \\
\text { MgO; } \mathrm{K}_{2} \mathrm{O} ; \mathrm{P}_{2} \mathrm{O}_{5} ; \mathrm{SO}_{3} ; \mathrm{TiO}_{2} \\
\mathrm{MnO} ; \mathrm{Cl} ; \mathrm{Rb}_{2} \mathrm{O} ; \mathrm{Co}_{3} \mathrm{O}_{4} ;\end{array}$ \\
\hline $\begin{array}{l}\text { Embalagens de } \\
\text { produtos } \\
\text { químicos }\end{array}$ & $\begin{array}{c}\text { Setor de } \\
\text { beneficiamento }\end{array}$ & $\begin{array}{c}\text { Gás toxin= } 1 \\
\text { pastilha para cada } \\
20 \text { sacos } \\
\text { Formigram }=3 \mathrm{~L} \\
\text { para } 600 \mathrm{~L} \text { de água }\end{array}$ & $\begin{array}{l}\text { Época de } \\
\text { plantio do } \\
\text { arroz (set à } \\
\text { mar) }\end{array}$ & Sólido & $\begin{array}{l}\text { PEAD MONO (polietileno), } \\
\text { COEX (poliamida polietileno), } \\
\text { PET (Tereftalato de Etileno) e } \\
\text { Embalagem Metálica (aço). }\end{array}$ \\
\hline $\begin{array}{l}\text { Estopa com óleo } \\
\text { lubrificante }\end{array}$ & $\begin{array}{l}\text { Setor de } \\
\text { elétrica e } \\
\text { consumo }\end{array}$ & $\begin{array}{l}5 \text { tonéis de } 200 \\
\text { litros ao mês }\end{array}$ & Diário & Sólido & $\begin{array}{l}\text { Algodão, poliéster, ácido } \\
\text { orgânico, cetona }\end{array}$ \\
\hline Graxa & $\begin{array}{l}\text { Setor de } \\
\text { elétrica e } \\
\text { consumo }\end{array}$ & $\begin{array}{l}5 \text { tonéis de } 200 \\
\text { litros ao mês }\end{array}$ & Diário & Pastoso & $\begin{array}{l}\text { Óleo mineral ou sintético, } \\
\text { agente espessante }\end{array}$ \\
\hline Óleo lubrificante & $\begin{array}{l}\text { Setor de } \\
\text { elétrica e } \\
\text { consumo }\end{array}$ & $\begin{array}{l}5 \text { tonéis de } 200 \\
\text { litros ao mês }\end{array}$ & Diário & Pastoso & $\begin{array}{l}\text { compostos oxigenados (ácidos } \\
\text { orgânicos e cetonas), } \\
\text { compostos aromáticos } \\
\text { polinucleares de viscosidade } \\
\text { elevada, resinas e lacas. }\end{array}$ \\
\hline Filtro de óleo & Oficina & $\begin{array}{c}5 \text { tonéis de } 200 \\
\text { litros ao mês }\end{array}$ & Diário & Sólido & Carcaça, papel especial, óleo \\
\hline
\end{tabular}




\section{Revista Eletrônica em Gestão, Educação e Tecnologia Ambiental} REGET/UFSM (e-ISSN: 2236-1170).

\begin{tabular}{|c|c|c|c|c|c|}
\hline Fios elétricos & $\begin{array}{l}\text { Setor de } \\
\text { elétrica }\end{array}$ & $\begin{array}{l}\text { Uma caixa grande } \\
\text { de papelão ao ano }\end{array}$ & Diário & Sólido & Plástico, cobre \\
\hline Impurezas & Laboratório & $\begin{array}{l}1 \text { saco plástico de } \\
5 \text { litros ao dia }\end{array}$ & Diário & Sólido & $\begin{array}{c}\text { Grão de arroz quebrado e/ou } \\
\text { danificado, manchados, } \\
\text { gessados, materiais estranhos, } \\
\text { etc. }\end{array}$ \\
\hline $\begin{array}{l}\text { Lâmpadas } \\
\text { fluorescentes }\end{array}$ & $\begin{array}{l}\text { Todos os } \\
\text { setores }\end{array}$ & $\begin{array}{l}1.040 \text { unidades } \\
\text { ao ano }\end{array}$ & Diário & Sólido & $\begin{array}{c}\text { Vapor de } \mathrm{Hg}(20 \mathrm{mg}), \mathrm{Ch}, \mathrm{Cr}, \mathrm{Mg} \\
\mathrm{Ni}, \mathrm{Cd}, \mathrm{Ba}, \mathrm{Sb}\end{array}$ \\
\hline Latas de tinta & $\begin{array}{l}\text { Setor de } \\
\text { pintura }\end{array}$ & $1 / 2$ tonel ao mês & Diário & Sólido & Alumínio \\
\hline Lodo de tinta & $\begin{array}{l}\text { Setor de } \\
\text { pintura }\end{array}$ & 200 litros ao mês & Diário & Pastoso & $\begin{array}{l}\text { Resina, pigmento, aditivo, } \\
\text { solventes }\end{array}$ \\
\hline Madeira & Marcenaria & $3 \mathrm{~m}^{3}$ ao mês & Diário & Sólido & $\mathrm{C}, \mathrm{H}, \mathrm{O}, \mathrm{N}$, celulose, lignina \\
\hline Poeira & $\begin{array}{c}\text { Processo de } \\
\text { pré-limpeza do } \\
\text { arroz }\end{array}$ & $\begin{array}{c}5 \text { cargas caminhão } \\
\text { ao mês }\end{array}$ & Diário & Sólido & \\
\hline Pneu & $\begin{array}{l}\text { Setor de } \\
\text { lavagem }\end{array}$ & 1 caminhão ao ano & Diário & Sólido & $\begin{array}{c}\text { Borracha, aço, tecido de náilon } \\
\text { ou poliéster }\end{array}$ \\
\hline Pilhas & $\begin{array}{l}\text { Setor de } \\
\text { consumo }\end{array}$ & $\begin{array}{c}1 / 2 \text { garrafa pet ao } \\
\text { mês }\end{array}$ & Semanal & Sólido & $\mathrm{Hg}, \mathrm{Pb}, \mathrm{Cd}, \mathrm{In}$ \\
\hline Plástico & $\begin{array}{c}\text { Setor de } \\
\text { beneficiamento } \\
\text { e escritórios }\end{array}$ & $1.200 \mathrm{Kg}$ ao mês & Diário & Sólido & Polímeros \\
\hline Papelão & $\begin{array}{l}\text { Setor de } \\
\text { consumo }\end{array}$ & & Diário & Sólido & Fibras \\
\hline Papel & Escritórios & & Diário & Sólido & Fibras \\
\hline Resíduo orgânico & $\begin{array}{l}\text { Todos os } \\
\text { setores }\end{array}$ & $40 \mathrm{~m}^{3}$ & Diário & Sólido & Compostos orgânicos \\
\hline Tecnológico & $\begin{array}{l}\text { Todos os } \\
\text { setores }\end{array}$ & $2 \mathrm{~m}^{3}$ & Anual & Sólido & $\begin{array}{l}\text { Plástico, metal não ferroso } \\
\text { (chumbo, cádmio, berílio, } \\
\text { mercúrio), vidro, borracha, } \\
\text { placas eletrônicas (ouro, } \\
\text { platina, prata, paládio }\end{array}$ \\
\hline
\end{tabular}

Fonte: Dados coletados, 2010.

\subsection{Etapas dos processos produtivos na indústria de beneficiamento de arroz}

A seguir, será descrita a seqüência das etapas compreendidas desde a recepção da carga (do arroz úmido com casca) na indústria até a expedição do produto final beneficiado (Figura 1).

$1^{0}$ Etapa. Chegada do caminhão na indústria (recepção): Ao chegar à indústria, o motorista do caminhão recebe na portaria um "cartão senha", que corresponde a definição da carga (arroz, 


\section{Revista Eletrônica em Gestão, Educação e Tecnologia Ambiental REGET/UFSM (e-ISSN: 2236-1170).}

soja) e a fila do descarregamento desta. Os resíduos identificados nesta parte do processo foram as impurezas (material estranho, arroz sujo, arroz úmido, etc.), resultantes do processo da análise de pureza e umidade dos grãos.

$2^{0}$ Etapa. Pesagem e amostragem: Após a pesagem do caminhão são coletadas amostras representativas da carga e realiza-se a análise dos grãos em laboratório. Os principais parâmetros analisados no laboratório são pureza e umidade. Também é realizado o teste de rendimento em mini-engenho de provas; a classificação do produto e a verificação da porcentagem de grãos existentes. As amostras "verdes", como são chamadas, devem ser transportadas para secadoras no laboratório e, após resfriamento por 48 horas, novamente será realizada a análise do grão. Neste caso, o produto será enviado para a "caixa de depósito verde" que segue para os secadores na produção.

$3^{0}$ Etapa. Recepção na moega: Após a pesagem e a análise dos grãos, a carga será descarregada em "moegas de recepção". Através de "elevadores de caneca" o produto será transportado para as caixas reguladoras de fluxo, para a pré-limpeza e silo pulmão (local de armazenamento temporário dos grãos).

$4^{0}$ Etapa. Pré-limpeza: Após os grãos passam para pré-limpeza que tem como objetivo retirar as impurezas através de equipamentos como peneiras e ventiladores e preparar os grãos para a secagem. Após a pré-limpeza os grãos são depositados nos "silos pulmão". O principal resíduo identificado nesta parte do processo foi poeira.

$\mathbf{5}^{0}$ Etapa. Secagem: Na secagem, o aquecimento do ar tem a finalidade de diminuir a umidade e a capacidade evaporativa. Esta etapa é importante e necessita de cuidado permanente e rigoroso para o controle do aquecimento. Para o sistema de aquecimento, as fornalhas, utilizam como combustível a própria casca resultante do beneficiamento do arroz. Ao final da secagem, recomenda-se armazenar o grão antes da operação de beneficiamento, por um período de 48 a 72 horas em silos metálicos a granel. Nesta parte do processo os resíduos principais foram: cinza e casca de arroz.

$6^{0}$ Etapa. Limpeza: Para complementar a retirada de poeira e outros produtos leves o grão passa por um "flutuador" (equipamento que completa a retirada de poeira). Na seqüência passa pela máquina de "trieur" para separação dos grãos quebrados.

$7^{0}$ Etapa. Descascamento: 0 processo de descascamento tem o objetivo de descascar os grãos. Realiza-se o rompimento da casca dos grãos, produzindo casca e grãos esbramados. A casca será separada do grão integral por sucção. Os grãos esbramados ou integrais resultantes serão novamente selecionados com a finalidade de separar os grãos que continuam com casca, conhecidos como "marinheiros".

A separação dos "marinheiros", que retornam para o descascador quantas vezes forem necessárias até a perda da casca, será realizada em equipamentos baseados na diferença de densidade, já que a densidade dos grãos aumentam após ser descascado. Encerrando o processo de descascamento, obtêm-se o grão esbramado que pode ser comercializado na forma de arroz integral ou ser submetido ao processo de brunimento e polimento. Os resíduos considerados nesta parte do processo foram às cascas. 


\section{Revista Eletrônica em Gestão, Educação e Tecnologia Ambiental REGET/UFSM (e-ISSN: 2236-1170).}

$8^{0}$ Etapa. Brunimento: $O$ processo de brunimento consiste em remover o germe e a película que envolve a cariopse no grão, utilizando as pedras dos brunidores. A parte que resta deste processo será o grão brunido e o farelo (germe e película removidos da periferia do grão). Para melhorar o brilho do grão, este passa para o polidor à água complementando o polimento. 0 resíduo avaliado nesta parte do processo foi o farelo.

$9^{0}$ Etapa. Seleção: Após o brunimento, o arroz passa pelo processo de seleção, que consiste na separação de fragmentos e de grãos com defeitos melhorando a qualidade do produto e, conseqüentemente, elevando o preço na comercialização. Nesse processo serão removidos as matérias estranhas ou fragmentos que não foram retirados na limpeza, através de peneiras e "trieurs". Nesta seleção será classificado o arroz de acordo com o grupo, subgrupos, classes e tipos.
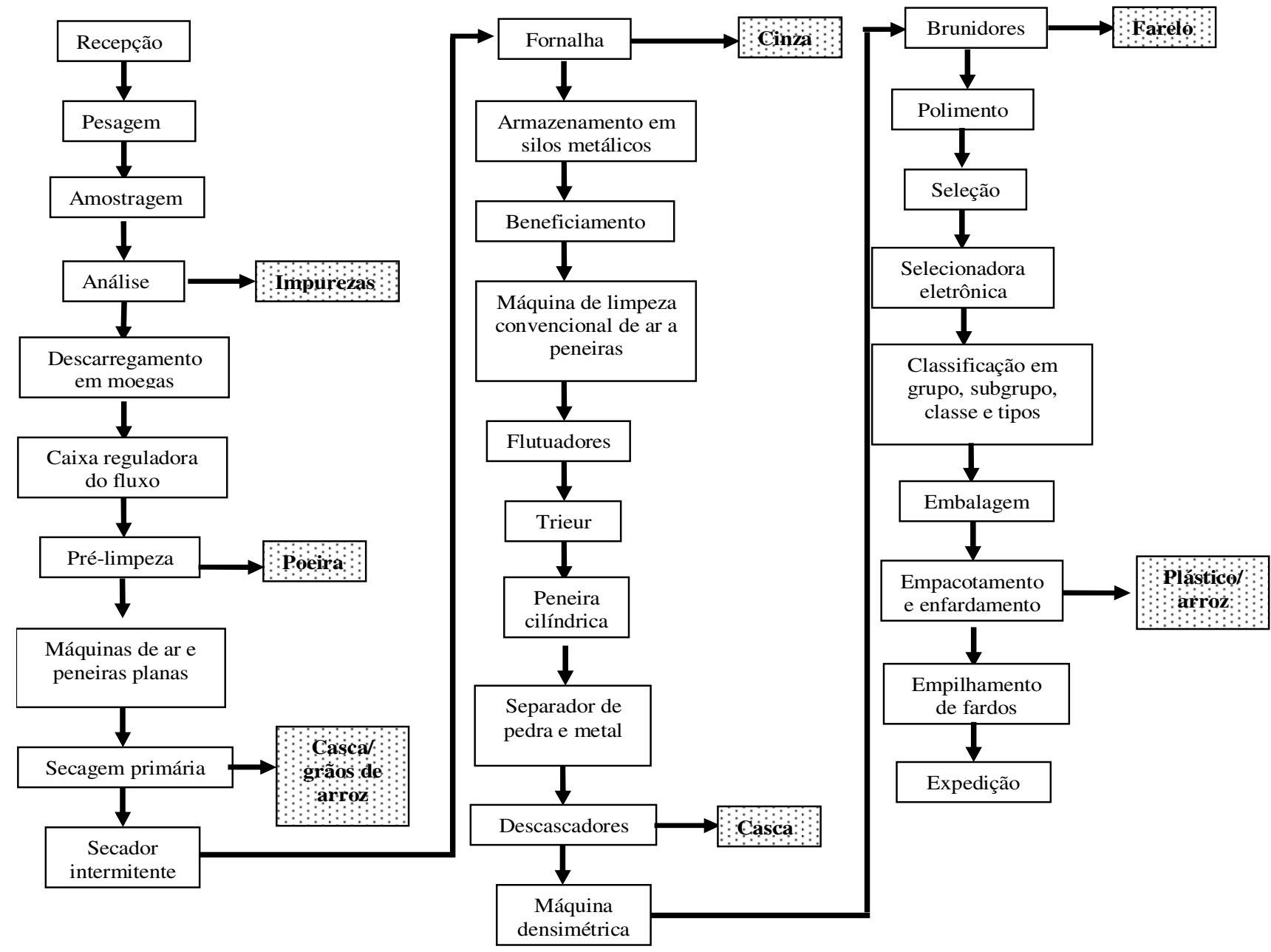

Beneficiamento do arroz: : :

Resíduos sólidos

Figura 1. Fluxograma do Beneficiamento do Arroz e Identificação dos Resíduos Sólidos Gerados em cada Processo

Fonte: Dados coletados, 2010. 


\section{Revista Eletrônica em Gestão, Educação e Tecnologia Ambiental REGET/UFSM (e-ISSN: 2236-1170).}

$10^{\circ}$ Etapa. Embalagem: $O$ processo de empacotamento é totalmente automatizado e segue a normatização da Legislação Brasileira. Nesta etapa, os resíduos considerados foram às embalagens que estouram.

\subsection{Identificação e destinação de resíduos gerados na agroindústria de beneficiamento de arroz}

A seguir, será apresentada a destinação dos resíduos gerados pela agroindústria de arroz estudada:

a) Casca de arroz: é armazenada em local aberto e reutilizada nas caldeiras/fornalhas da própria empresa. A parte destinada a produtores e empresas de avicultura são armazenadas em sacos para após serem transportadas.

b) Cinza: é armazenada no pátio da empresa ao ar livre. Os produtores a utilizam como "adubo" em suas lavouras.

c) Embalagens de produtos químicos: são armazenadas no pátio da empresa ao ar livre. A empresa contrata uma prestadora de serviços que faz a destinação final do resíduo corretamente.

d) Estopas com óleo lubrificante: são armazenadas em lixeiras. A empresa contrata uma prestadora de serviços que dá a destinação final do resíduo corretamente.

e) Graxas: são armazenadas em tonel. A empresa contrata uma prestadora de serviços que dá a destinação final do resíduo corretamente.

f) Óleo lubrificante: é armazenado em tonel. A empresa contrata uma prestadora de serviços que realiza a destinação final do resíduo corretamente.

g) Filtros de óleo: são armazenados em tambores. A empresa contrata uma prestadora de serviços que realiza a destinação final do resíduo corretamente.

h) Fios elétricos: são armazenados em caixas de papelão. A empresa contrata uma prestadora de serviços para a destinação final do resíduo corretamente.

i) Impurezas: são armazenadas em caixa de papelão. As impurezas retornam para o processo de beneficiamento.

j) Lâmpadas fluorescentes: são empacotadas e colocadas em caixas de papelão em depósito para posteriormente serem encaminhadas para uma prestadora de serviços que realizará a destinação final do resíduo corretamente.

k) Latas de tinta: não possuem um acondicionamento propriamente dito, são amassadas e depositadas no pátio da empresa. Posteriormente, são encaminhadas a uma prestadora de serviços responsável pela destinação final do resíduo corretamente. 


\section{Revista Eletrônica em Gestão, Educação e Tecnologia Ambiental REGET/UFSM (e-ISSN: 2236-1170).}

I) Lodo de tinta: é armazenado em tonel. A empresa contrata uma prestadora de serviços que realiza a destinação final do resíduo corretamente.

m) Madeira: o que pode ser reaproveitado a empresa utiliza no setor de marcenaria, já o que não pode mais ser reutilizado é depositado no pátio da empresa para posteriormente ser encaminhado a uma empresa prestadora de serviços que será responsável pela destinação final do resíduo corretamente.

n) Poeira: é armazenada em tonéis e sacos no pátio da empresa, em área coberta.

o) Pneus: não possui um armazenamento especifico, ficam depositados no setor de lavagem da empresa e, posteriormente, são encaminhados para uma empresa de reciclagem.

p) Pilhas: são armazenadas em garrafas pet. A empresa contrata uma prestadora de serviços que realiza a destinação final do resíduo corretamente.

q) Plásticos: são armazenados em lixeiras e encaminhados para o setor de lã onde são separados e acondicionados em fardos. Posteriormente, são vendidos para empresas recicladoras.

r) Papelão: é armazenado em lixeiras e encaminhado para o setor de lã onde é separado e acondicionado em fardos. Posteriormente, são vendidos para empresas recicladoras.

s) Papel: é armazenado em lixeiras e encaminhado para o setor de lã onde é separado e acondicionado em fardos. Posteriormente, é vendido para empresas recicladoras.

t) Resíduos orgânicos: são armazenados em lixeiras e temporariamente armazenados no pátio da empresa onde serão recolhidos pela coleta municipal.

u) Tecnológico: é armazenado no setor de lã da empresa e encaminhado a uma prestadora de serviços que dá a destinação final do resíduo corretamente.

\subsection{Proposição de melhorias para destinação de resíduos contaminantes}

O resíduo agroindustrial depois de produzido necessita de destinação adequada evitando potenciais problemas ambientais (Pelizer et al., 2007). Essa preocupação com o destino final dos resíduos produzidos visa minimizar os perigos das emissões quando o produto se encontra em fase de eliminação ou descarte final (Manzini \& Vezzoli, 2008).

Uma agroindústria que beneficia alimentos produz uma série de resíduos, alguns altamente impactantes, com alto valor de reutilização, que podem ser utilizados na manufatura de outros produtos e, também, como insumo no processo produtivo, possibilitando a logística reversa. Isto possibilita uma minimização dos impactos ambientais causados no ambiente e, também, uma maior eficiência econômica da empresa. 


\section{Revista Eletrônica em Gestão, Educação e Tecnologia Ambiental REGET/UFSM (e-ISSN: 2236-1170).}

Segundo Manzini e Vezzoli (2008) os materiais residuais da indústria podem ser reprocessados e transformados em matéria prima secundária ou incinerados potencializando o seu valor energético.

Dos resíduos gerados na agroindústria de beneficiamento de arroz, os principais que podem reduzir os impactos socioambientais e produzidos em grande escala são a casca de arroz e a cinza (Quadro 1).

Segundo Della et al. (2005), para cada tonelada de arroz em casca, 23\% correspondem a casca, e $4 \%$ correspondem a cinzas. Isso evidencia o problema ambiental causado pelo excesso da casca de arroz que precisa ser destinada.

As cascas de arroz produzidas são reutilizadas na agroindústria como combustível através da queima na caldeira. Considerada uma solução para os impactos ao meio ambiente, causados pelo problema do resíduo de casca de arroz, é a geração de energia elétrica (Dias, 2011). Além disso, os produtores rurais também recolhem parte da casca para utilização em suas propriedades. De acordo com Dias (2011) a compostagem é um dos destinos mais utilizado para este resíduo.

Alguns autores reutilizam esse resíduo obtendo filme polimérico (Ferreira, 2005) que são utilizados em aparelhos ópticos e semicondutores como componentes ativos na proteção de cobertura e na produção de bioinseticida a base de Bacillus thuringiensis (Pelizer, 1997).

Com a combustão da casca do arroz nas fornalhas para geração de energia tem-se a cinza como principal resíduo. A maior parte deste resíduo gerado pela agroindústria é reutilizado nas lavouras como adubo. Segundo Dias (2011) este resíduo não deve ser descartado diretamente no meio ambiente.

Para alguns autores, a cinza pode ser utilizada na indústria cerâmica principalmente como matéria prima na fabricação de vidros, refratários, tubos cerâmicos, isolantes térmicos, abrasivos e na construção civil como componente em cimentos, concretos e argamassas (Della et al., 2006) e também como fonte de nutrientes para a produção de aveia em solos arenosos (Silva, 2005).

Quadro 1. Síntese dos resíduos sólidos gerados na indústria debeneficiamento de arroz, destino e proposição de alternativa de destinação sugerida pela literatura

\begin{tabular}{|c|c|c|}
\hline Resíduo & $\begin{array}{l}\text { Destino dado pela indústria de } \\
\text { beneficiamento de arroz estudada }\end{array}$ & $\begin{array}{lcc}\text { Proposição } & \text { de alternativa } & \text { de } \\
\text { destinação } & \text { sugerida pela } \\
\text { literatura } & & \end{array}$ \\
\hline Casca de arroz & $\begin{array}{l}\text { fornalha; produtores e empresas de } \\
\text { avicultura }\end{array}$ & energia elétrica; compostagem \\
\hline Cinza & adubo & $\begin{array}{l}\text { Indústria cerâmica; Construção } \\
\text { civil; }\end{array}$ \\
\hline $\begin{array}{l}\text { Embalagem de produtos } \\
\text { químicos }\end{array}$ & prestadora de serviços & \\
\hline Estopa com óleo lubrificante & prestadora de serviços & \\
\hline Graxa & prestadora de serviços & \\
\hline Filtro de óleo & prestadora de serviços & \\
\hline Fios elétricos & prestadora de serviços & \\
\hline Impurezas & Retornam ao beneficiamento & \\
\hline Lâmpadas fluorescentes & prestadora de serviços & \\
\hline
\end{tabular}




\section{Revista Eletrônica em Gestão, Educação e Tecnologia Ambiental}

REGET/UFSM (e-ISSN: 2236-1170).

\begin{tabular}{|l|l|l|}
\hline Latas de tinta & prestadora de serviços & \\
\hline Lodo de tinta & prestadora de serviços & Fornalha; \\
\hline Madeira & prestadora de serviços & \\
\hline Poeira & armazenados & $\begin{array}{l}\text { Matéria prima para a manufatura } \\
\text { de outros produtos. }\end{array}$ \\
\hline Pneu & reciclagem & \\
\hline Pilhas & prestadora de serviços & $\begin{array}{l}\text { Matéria prima para a manufatura } \\
\text { de outros produtos. }\end{array}$ \\
\hline Plástico & reciclagem & $\begin{array}{l}\text { Matéria prima para a manufatura } \\
\text { de outros produtos. }\end{array}$ \\
\hline Papelão & reciclagem & $\begin{array}{l}\text { Matéria prima para a manufatura } \\
\text { de outros produtos. }\end{array}$ \\
\hline Papel & reciclagem & \\
\hline Resíduo orgânico & coleta municipal & \\
\hline Tecnológico & prestadora de serviços & \\
\hline
\end{tabular}

Fonte: Autores (2010).

\section{CONCLUSÕES}

O mapeamento de resíduos sólidos gerados no processo de beneficiamento de uma agroindústria de arroz é o processo inicial para a introdução de um sistema de gestão ambiental. 0 próximo passo seria o reaproveitamento dos resíduos gerados na fabricação de outros produtos e na utilização destes resíduos novamente no processo como matéria prima (insumos) através do processo de logística reversa.

A reutilização dos resíduos possibilita uma redução do impacto ambiental causado e também uma economia decorrente da redução dos custos de produção.

O diagnóstico realizado permite a empresa conhecer melhor o seu funcionamento e assumir um compromisso com a melhoria contínua fazendo uma revisão periódica dos resíduos sólidos gerados no processo produtivo. Além disso, a empresa tem a possibilidade de investir em pesquisa e desenvolvimento de novos produtos produzidos com o reaproveitamento dos resíduos dessa mesma atividade. Esta é uma opção estratégica ambientalmente correta que tem sido adotada por algumas organizações públicas e privadas.

\section{REFERÊNCIAS BIBLIOGRÁFICAS}

ALBUQUERQUE, J.L. Gestão Ambiental e Responsabilidade Social: Conceitos, Ferramentas e Aplicações. São Paulo: Atlas, 2010, 336p.

ANDRADE, T. C. S. \& CHIUVITE, T. B.S. Meio Ambiente: Um bom negócio para a indústria - Práticas de Gestão Ambiental. 1. ed. São Paulo:Tocalino, 2004. 161 p. 


\section{Revista Eletrônica em Gestão, Educação e Tecnologia Ambiental REGET/UFSM (e-ISSN: 2236-1170).}

DELLA, V.P.; KÜHN, I.; HOTZA, D. Reciclagem de Resíduos Agro-Industriais: Cinza de Casca de Arroz como Fonte Alternativa de Sílica. Cerâmica Industrial, v.10, n.2, p. 22-25, 2005.

DELLA, V. P.; HOTZA, D. ;JUNKES, J. A.; OLIVEIRA, A. P. N. Estudos comparativos entre sílica obtida por lixívia ácida da casca de arroz e sílica obtida por tratamento térmico da cinza de casca de arroz. Química Nova, v. 29, n. 6, p. 1175-1179, 2006.

DIAS, R. Marketing Ambiental: ética, responsabilidade social e competitividade nos negócios.1. ed. São Paulo: Atlas, 2009. 204 p.

DIAS, M. F. P.; PEDROZO, E. A.; ANICET, C. N. Desafios e respostas inovadoras sustentáveis da agroindústria arrozeira brasileira. Revista em Agronegócios e Meio Ambiente, v. 4, n.1, p. 57-77, 2011.

FERREIRA, C. S. Desenvolvimento do processo de obtenção de filme polimérico a partir da cinza da casca de arroz. 2005. 75f. Dissertação (Mestrado). Universidade Federal de Santa Catarina. Florianópolis 2005.

FREIRE, R. S.; PELEGRINI, R.; KUBOTA, L. T.; DURAN, N.; PERALTA-ZAMORA, P. Novas tendências para o tratamento de resíduos industriais contendo espécies organocloradas. Química Nova, v. 23, n. 4, p. 504$511,2000$.

IBGE. Produção Agrícola Municipal 2009. Acesso em 10.05.2011. Disponível em: http://www.ibge.gov.br/cidadesat/topwindow.htm?1.

IBGE. População do Município de São Sepé 2010. Acesso em 10.05.2011. Disponível em: http://www.ibge.gov.br/cidadesat/topwindow.htm?1

MALHOTRA, N. Pesquisa de Marketing: Uma Orientação Aplicada. 3. Ed. Porto Alegre: Bookmann, 2001. $719 \mathrm{p}$.

MANZINI, E. \& VEZZOLI, C. O Desenvolvimento de Produtos Sustentáveis: Os Requisitos Ambientais dos Produtos Industriais. São Paulo: Editora Universidade de São Paulo, 2008. 367 p. 


\section{Revista Eletrônica em Gestão, Educação e Tecnologia Ambiental REGET/UFSM (e-ISSN: 2236-1170).}

MENEZES, R. R.; NEVES, G. A.; FERREIRA, H. C. O estado da arte sobre o uso de resíduos como matériasprimas cerâmicas alternativas. Revista Brasileira de Engenharia Agrícola e Ambiental, v.6, n.2, p .303-313, 2002.

NICOLELLA, G.; MARQUES, J. F.; SKORUPA, L. A. Sistema de Gestão Ambiental: aspectos teóricos e análise de um conjunto de empresas da região de Campinas, SP. Jaguariúna: Embrapa Meio Ambiente, 2004. 42p.-(Embrapa Meio Ambiente. Documentos, 39).

PELIZER, L.H. Estudo da influência da atividade de água na fermentação em estado sólido de Bacillus thuringiensis. 1997. 104f. Dissertação (Mestrado). Universidade Estadual de São Paulo, São Paulo. 1997.

PELIZER, L. H.; PONTIERI, M. H.; MORAES, I. de O. Utilização de resíduos agro-industriais em processos biotecnológicos como perspectiva de redução do impacto ambiental. Journal of Technology Management \& Innovation, v 2, p. 118-127, 2007.

SENNA, A.J.T \& LHAMBY, A. R. Marketing ambiental em agronegócios: um estudo de caso sobre o selo ambiental da lavoura do arroz. In: Anais do I Congresso Brasileiro de Gestão Ambiental, 2010, Bauru. Anais...Bauru: IBEAS, 2010.CD Rom.

SILVA, P. R. S. \& AMARAL, F. G. Avaliação dos custos de geração de rejeitos em uma indústria do setor metal-mecânico. In: XXIV Encontro Nacional de Engenharia de Produção, 2004, Florianópolis. Acesso em: 30/08/2011. Disponível em: http://www.abepro.org.br/biblioteca/ENEGEP2004_Enegep1002_0285.pdf.

SILVA, F. F. Aplicação de cinza da casca de arroz e de água residuária de indústria de fecularia de mandioca na cultura da aveia. 2005. 86f. Tese (Doutorado). Universidade Estadual de Maringá, Maringá, 2005.

SILVA, F. S.; CORRÊA, P. C.; GONELI, A. L. D.; RIBEIRO, R. M; JÚNIOR, P. C. A. Efeito do beneficiamento nas propriedades físicas e mecânicas dos grãos de arroz de distintas variedades. Revista Brasileira de Produtos Agroindustriais, v.5, n.1, p.33-41, 2003.

VIEIRA, N. R. A. \& CARVALHO, J. L.V. Qualidade tecnológica. In: Vieira, N. R. A.; Santos, A. B.; Sant Ana, E. P. A cultura do arroz no Brasil. EMBRAPA Arroz e Feijão: Santo Antônio de Goiás, p. 582-604, 1999. 